\title{
Continence and complications rates after male slings as primary surgery for post-prostatectomy incontinence: A systematic review
}

\author{
Maria Angela Cerruto, Carolina D'Elia, Walter Artibani \\ Department of Surgery Urology Clinic, University of Verona, Italy.
}

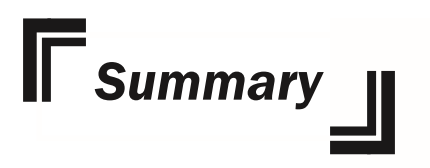

Objectives: to analyze continence and complications rates after male slings as first line surgical treatment, in order to improve patient counseling for the management of SUI postprostatectomy.

Method: A MedLine search using specified search terms was done on January 23, 2012. This research rendered 160 records.

Results: No controlled trial was available for analysis. The majority of papers dealing with outcome and complications came from a few centres. At a median follow-up of 15 months the pooled cure rates for all kinds of slings was 77.4; in the AdVance group the pooled cure rates was $72.5 \%$; in the InVance group it was $74.2 \%$ while in the Remeex group it was $84.3 \%$.

Conclusions: Only a few number observational studies addressed review selection criteria. The pooled overall cure rates is high but there are no data concerning reliable pre- and postoperative prognostic factors affecting treatment failure and complications rates, thus it is not possible to have suitable criteria for a better patient selection. The statistically pooled results obtained should be interpreted with caution because of several limitations due to several study selection limitations: observational study design, few number of analysed studies, heterogeneity, lack of outcome definition and standardisation, between-study variability, high risk of bias.

KEY WORDS: Sling; Male incontinence; Radical prostatectomy; Continence; Complications.

\section{INTRODUCTION}

Radical prostatectomy (RP) is the most common treatment option for prostate cancer, with more than 80000 RPs annually in the USA (1). Urinary incontinence (UI) is a common and costly complication in men after RP, often adversely affecting their quality of life (QoL) (2). Despite improvements in surgical techniques and a better understanding of pelvic anatomy, the reported stress urinary incontinence (SUI) rates are between 5\% and $48 \%$ (3). Conservative treatment of the urinary leakage represents the first line management of UI after RP, but the value of the various conservative approaches to treat postprostatectomy UI after RP remains uncertain (4). The last Cochrane systematic review on this topic found that there was conflicting information about the benefit of pelvic floor muscle training for either prevention or treatment of urine leakage after prostate surgery. More research of better quality is needed to assess conservative managements (4). When conservative treatments are unsuccessful after a reasonable period of time (e.g. 8-12 weeks), invasive therapies should be considered (5). According to the last International Consultation on Incontinence Recommendations, for SUI due to sphincter incompetence the recommended option is the artificial urinary sphincter (AUS) (Grade B); other options, such as a male sling, may be considered (Grade C) (5). These low grades of recommendation can be explained by the fact that, although there are several options for surgical treatment of UI after prostatectomy, surprisingly only one randomised clinical trial was identified in the literature, comparing AUS implantation and injectable treat- 
ment with Macroplastique (6). For other surgical procedures such as male slings, Pro-ACT system, other bulking agents and stem-cell therapy, only non-randomised studies were identified (7), making impossible to answer questions about treatment comparison in terms of efficacy, safety, complications and long term results.

Despite the lack of information, when patients seek effective and durable treatment to achieve a continence status, it is necessary to adequately make aware them of continence rates and all possible complication of any proposed treatment as first line surgical option. The aim of this review was to analyze continence and complications rates after male slings as first line surgical treatment, in order to improve patient counseling for the management of SUI postprostatectomy.

\section{Methods}

The Preferred Reporting Items for Systematic Reviews and Meta-Analyses (PRISMA) checklist was used to help guide this report (8). We conducted a PubMed database search through January 2012 for relevant prospective cohort studies and case series that met the following inclusion criteria: English language; adults with SUI postprostatectomy who underwent male slings as first surgical option for continence recovery; studies carried out on $\geq 20$ patients with a mean follow-up of $\geq 1$ year;because the majority of papers dealing with outcome and complications came from a few centres, only the most recent publication(s) from each centre were included to avoid the same patients being presented several times.

Multiple free-text searches were performed including the following terms: Suburethral Slings, Suburethral Sling, Transobturator Tape, Transobturator Tapes, Transobturator Suburethral Tape, Trans-Obturator Tape, Male sling, Male slings, Argus sling, Advance sling, Invance sling, Remeex sling, Urinary Incontinence, Urinary Stress Incontinence, Post Prostatectomy, Post-prostatectomy, Prostatectomy, Prostatectomies, Suprapubic Prostatectomies, Suprapubic Prostatectomy, Retropubic Prostatectomies, Retropubic Prostatectomy. In addition, other significant studies cited in the reference lists of the selected papers were considered. Both authors independently reviewed all records by title and abstract followed by full-text articles for those meeting the screening criteria. Both authors independently abstracted data on study details (authors, year of publication, journal, location, study design), patient characteristics (age, length of follow-up, time period of surgery, type of prostatectomy), sling types, outcomes (overall cure rates, complications rates). A single reviewer (MAC) assessed risk of bias at the study level. The Downs-Black quality assessment tool (9) was used for nonrandomized studies; a score $\geq 17$ of 31 was considered higher quality.

Few studies presented their original data in a format amenable to meta-analysis. Articles that presented data as a median and range were converted to means according to Hozo et al. (10). A single weight-adjusted mean or proportion for each variable or outcome was computed for each of the nonrandomized studies. To derive pooled estimates of proportions for the outcomes explored, random effects models were used. Pooling was conducted using Comprehensive Meta Analysis Version 2.2.046 (Englewood, NJ). Given that this review assessed measures of prevalence, publication bias was not evaluated.

\section{RESULTS AND DISCUSSION}

From screening 160 records, 49 full-text articles were retrieved with only 5 articles included in the systematic review (Figure 1). The 5 included articles involved 356 participants living in 8 countries with a median followup after sling implant of 15 months (interquartile range, 12-21) and sling surgeries conducted between 2002 and 2009. Patients' mean age at time of surgery was 68.06 (standard deviation, 1.37) years. Study characteristics and quality are summarized in Table 1 (11-15).

Figure 1.

Preferred Reporting Items for Systematic Reviews and Meta-Analyses (PRISMA) flow diagram.

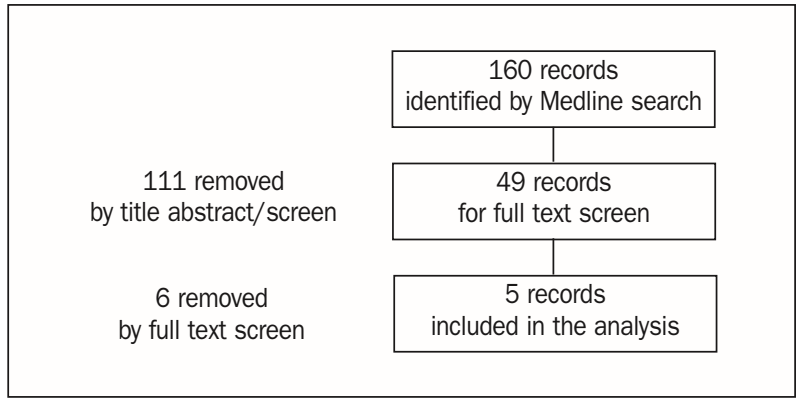

Table 1.

Characteristics of included observational studies.

\begin{tabular}{|c|c|c|c|c|c|c|c|c|c|c|}
\hline Source & $\begin{array}{c}\text { Publication } \\
\text { year }\end{array}$ & Journal & Nation & $\begin{array}{l}\text { Patient } \\
\text { number }\end{array}$ & $\begin{array}{l}\text { Time period } \\
\text { of surger }\end{array}$ & $\begin{array}{c}\text { RP rate } \\
(\%)\end{array}$ & $\begin{array}{c}\text { Patient } \\
\text { mean age }\end{array}$ & Sling type & $\begin{array}{c}\text { Mean } \\
\text { follow-up }\end{array}$ & $\begin{array}{c}\text { Risk } \\
\text { of bias }\end{array}$ \\
\hline Grise $P$, et al. (11) & 2011 & Urology & France & 103 & $2007-2009$ & 94.8 & 69.4 & I-STOP TOMS & 12 & high \\
\hline Cornu JN, et al. (12) & 2011 & BJU Int & France & 136 & $2007-2009$ & 92 & 67.4 & AdVance & 21 & high \\
\hline Cornel EB, et al. (13) & 2010 & J Urol & The Netherlands & 35 & $2007-2008$ & 80 & 68.5 & AdVance & 12 & high \\
\hline Gallagher BL, et al. (14) & 2007 & Urology & USA & 31 & 2002-2005 & 94 & 66 & InVance & 15 & high \\
\hline Sousa-Escandon A, et al. (15) & 2007 & Eur Urol & $\begin{array}{c}\text { Spain, Italy, } \\
\text { Greece, Germany, } \\
\text { Portugal }\end{array}$ & 51 & $2002-2005$ & 84.3 & 69 & Remeex & 32 & high \\
\hline
\end{tabular}


Figure 2.

Pooled analysis of reported overall cure rates.

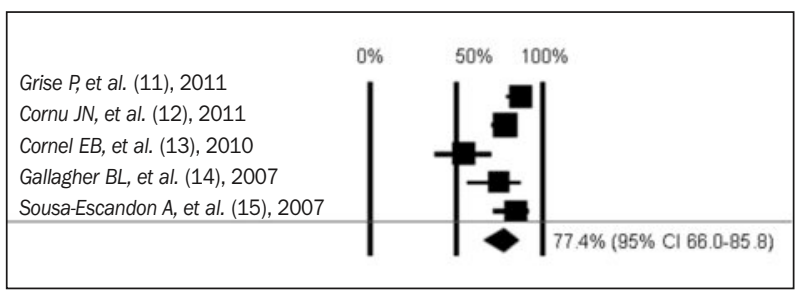

The types of slings considered were: the 4-arm I-STOP TOMS transobturator male sling (CL Medical) (11) (that is an adapted version of the 2-arm TOMS bulbar sling) (16); the AdVance sling $(12,13)$ (a retrourethral transobturator sling working by relocating the lax and descended supporting structures of the posterior urethra and sphincter region after prostate surgery into the former preprostatectomy position (17); the InVance sling (American Medical System) (14) (a nonadjustable sling system characterised by a silicon-coated polyester sling positioned under the bulbar urethra via a perineal incision to obtain a compression (18); the Remeex system (15) (a readjustable sling positioned under the bulbar urethra (19). Figure 2 pooled the continence rates achieved after the analysed sling procedures. At a median follow-up of 15 months the pooled cure rates for all kinds of slings was $77.4 \%$ (95\% CI 66.0-85.8); in the AdVance group the pooled cure rates was 72.5 (95\% CI 65.0-68.8); in the InVance group it was $74.2 \%$ (95\% CI $56.3-86.5)$ while in the Remeex group it was $84.3 \%$ (95\% CI 71.6-92). These statistically pooled results should be interpreted with caution because of several limitations due to several study selection limitations: study design, number of analysed studies, betweenstudy variability, high risk of bias. Concerning overall complications rate it was impossible to obtain this information. Grise et al. did not report complications, such as bladder perforation, intraoperative bleeding (> $200 \mathrm{~mL}$ ), or nerve, bowel, or vascular injury, occurred during the implant of the I-STOP TOMS male sling, except for wounding of the corpus cavernosum in $4 \%$ of patients (11). The authors reported a successful catheter removal 48 hours after surgery in $98.9 \%$ of patients. Moreover, $97.3 \%-100 \%$ were free of urinary tract infection at the different follow-up visits, and 96.5\%-100.0\% of the patients had not experienced urinary tract infection in the month before the visits. Immediately after the AdVance implant, Cornu et al. (12) reported only two cases of dysuria, one case of perineal haematoma and two cases of perineal paresthesia. During follow-up 10\% of $10 \%$ of patients had perineal pain and $14 \%$ of patients had mild dysuria, but none require surgical management. In the other case series (13) complications developed in 2 patients, including sling infection and postoperative urinary retention in 1 each. In the InVance group (14) 4 patients (13\%) underwent sling removal; two removals were because of infection (both of these patients had undergone previous radiotherapy), one because of pain, and one because of the lack of improve- ment in continence, necessitating long-term clean intermittent catheterization. The average time to removal of the sling because of infection was 99 days (range 35 to 163). All these patients presented with pain and superficial infections. In the Remeex case series (15) the mesh was removed in 1 case owing to urethral erosion and the varitensor in 2 cases owing to infection. There were five (9.8\%) uneventful intraoperative bladder perforations at the postoperative period, and there were three mild perineal haematomas (5.9\%). Most patients felt perineal discomfort or pain, which was easily treated with oral medications.

\section{Conclusion}

The male slings approved for use currently include a variety of types: bone anchored slings, adjustable slings, and transobturator slings. This review tried to systematically assessed the outcomes of male slings used as the first line treatment, after conservative therapy failure, for the treatment of post-prostatectomy SUI. Only a few number of the observational studies published in the literature addressed review selection criteria. The pooled overall cure rates is high but there are no data concerning reliable pre- and postoperative prognostic factors affecting treatment failure and complications rates, thus it is not possible to have suitable criteria for a better patient selection.

The statistically pooled results obtained should be interpreted with caution because of several limitations due to several study selection limitations: observational study design, few number of analysed studies, heterogeneity, lack of outcome definition and standardisation, between-study variability, high risk of bias.

In order to better select patients for male slings in the management of post-prostatectomy SUI as first line treatment, it is mandatory to carried out both well designed randomized clinical trials and longitudinal cohort studies, using standardised protocols and outcome measures.

\section{References}

1. United States Agency for Healthcare Research and Quality. Healthcare Cost and Utilization Project (USA). Available at: http://hcupnet.ahrq.gov/. Accessed January 2012.

2. Haab F, Beley S, Cornu JN, et al. Urinary and sexual disorders following localised prostate cancer management. Bull Cancer. 2010; 97:1537-49.

3. Schröde A, Abrams P, Andersson KE, et al. Guidelines on urinary incontinence. In Arnheim AG, editor. EAU guidelines. Arnheim, the Netherlands: European Association of Urology. 2010; p.11-28.

4. Campbell SE, Glazener CM, Hunter KF, et al. Conservative management for postprostatectomy urinary incontinence. Cochrane Database Syst Rev. 2012; 1:CD001843.

5. Abrams P, Andersson KE, Birder L, et al. Fourth International Consultation on Incontinence Recommendations of the International Scientific Committee: Evaluation and Treatment of Urinary Incontinence, Pelvic Organ Prolapse, and Fecal Incontinence. Neurourol Urodyn. 2010; 29:213-240.

6. Imamoglu MA, Tuygun C, Bakirtas $H$, et al. The comparison of artificial urinary sphincter implantation and endourethral macroplas- 
tique injection for the treatment of postprostatectomy incontinence. Eur Urol. 2005; 47:209-13.

7. Silva LA, Andriolo RB, Atallah AN, da Silva EM. Surgery for stress urinary incontinence due to presumed sphincter deficiency after prostate surgery. Cochrane Database Syst Rev. 2011; (4):CD008306.

8. Moher D, Liberati A, Tetzlaf J, et al. Preferred reporting items for systematic reviews and meta-analyses: the PRIsMa statement. BMJ. 2009; 339:332-336.

9. Downs SH, Black N. The feasibility of creating checklist for assessment of the methodological quality both randomized and non-randomized studies of health care interventions. J Epidemiol Community Health. 1998; 52:377-384.

10. Hozo SP, Djubegovic B, Hozo I. Estimating the mean and variance from median, range and the size of the sample. BMC Med Res Methodol. 2005; 5:13.

11. Grise P, Vautherin R, Njinou-Ngninkeu B, et al. I-Stop TOMS Transobturator Male Sling, a Minimally Invasive Treatment for Post-prostatectomy Incontinence: Continence Improvement and Tolerability. Urology. 2012; 79:458-63.

12. Cornu JN, Sèbe P, Ciofu C, et al. Mid-term evaluation of the transobturator male sling for post-prostatectomy incontinence: focus on prognostic factors. BJU Int. 2011; 108:236-40.
13. Cornel EB, Elzevier HW, Putter H. Can advance transobturator sling suspension cure male urinary postoperative stress incontinence? J Urol. 2010; 183:1459-63.

14. Gallagher BL, Dwyer NT, Gaynor-Krupnick DM, et al. Objective and quality-of-life outcomes with bone-anchored male bulbourethral sling. Urology. 2007; 69:1090-4.

15. Sousa-Escandón A, Cabrera J, Mantovani F, et al. Adjustable suburethral sling (male remeex system) in the treatment of male stress urinary incontinence: a multicentric European study. Eur Urol. 2007; 52:1473-9.

16. Grise P, Geraud M, Lienhart J, et al. Transobturator male sling TOMS for the treatment of stress post-prostatectomy incontinence, initial experience and results with one year's experience. Int Braz J Urol. 2009; 35:706-713.

17. Rehder P, Gozzi C. Transobturator sling suspension for male urinary incontinence including post-radical prostatectomy. Eur Urol. 2007; 52:860-7.

18. Fassi-Fehri H, Bader L, Cherass A, et al. Efficacy of the InVanceTM male sling in men with stress urinary incontinence. Eur Urol. 2007; 51:498-503.

19. Sousa-Escandon A, Cabrera J, Mantovani F, et al. Externally readjustable sling for treatment of male stress urinary incontinence: points of technique and preliminary results. J Endourol. 2004; 18:113-8.

\section{Correspondence}

Maria Angela Cerruto, MD mariaangela.cerruto@univr.it

Carolina D’Elia, MD, FEBU (Corresponding Author)

karolinedelia@gmail.com

Walter Artibani, MD

walter.artibani@univr.it

Urology Clinic, Department of Surgery

University of Verona \& AOUI, p.le L Scuro 10 - 37134 Verona, Italy 